\title{
Authentic Leadership, Emotional Exhaustion and Job Satisfaction in Nigerian Hospitality Industry: the mediating Role of Psychological Ownership
}

\author{
*Linus Jonathan Vem, Goyit Meshach Gomam, Teresa M. Nmadu, \\ Pam B. Wurim \\ Faculty of Management Sciences, University of Jos, Nigeria.
}

\begin{abstract}
This study was conducted with the aim of evaluating ways of reducing emotional exhaustion and ensuring job satisfaction.This was done by examining the predictive role of authentic leadership, through the intervening role of psychological ownership in Nigerian hospitality industry. To achieve these objectives, 350 questionnaire were administered to frontline employees and their responses analyzed using Smart-PLS version 3.0. Finding reveals that authentic leadership negatively associates with emotional exhaustion, and positively with psychological ownership. The relationship between authentic leadership and job satisfaction was positive based on one tailed test but was found to be statistically insignificant. Employee psychological ownership was found a mediate the relationship between authentic leadership job satisfaction as well as emotional exhaustion indicating indirect relationship with job satisfaction and emotional exhaustion. We recommended that practionners in hospitality industry and other service related organisation should pay attention to the kind of leadership style in their organisatiion by grooming authentic leaders who should provide needed mitigating effect on their emotional exhaustion. Secondly, infusing sense of belonging increases employee psychological ownership, hence managers were encouraged to see leadership from the followers perspective to ensure job satisfaction and reduced emotional exhaustion.
\end{abstract}

Key Words: Authentic Leadership, Psychological ownership, Job Satisfaction and Emotional Exhaustion.

\section{Introduction}

One key component of a service job be it in public or private sector is its demand on employee emotion also known as emotional labour. Employees in Hospitality industry particularly the front-liners are expected to dispense service cheerfully at every given circumstance hence are vulnerable to stress (Lewig \& Dollard, 2003). Consistent with Callahan and McCollum (2002) this paper termed emotional labour as involving employees regulating their emotions in exchange for pay, which is sometimes done in spite of the potential risk to their health and well-being. Though emotional regulation is an implicit phenomenon among employees in the hospitality business (Francis, Kaldor, Shevlin, \& Lewis, 2004; Hall et al. 2010), should this continue without recourse to employees' personal feelings? It is worrisome that despite facing personal challenges at home and work, like any other employee, front-line workers are expected to manage their emotions and guests' as well (Martínez-iñigo, Totterdell, \& Alcover, 2007) offering assurance of quality service against all odds, making them highly susceptible to emotional exhaustion.

Emotional labour and Emotional exhaustion are two related phenomenon that often characterise the experiences of employees in the service sector, with emotional labour setting the pace for exhaustion (Martíneziñigo et al., 2007). These category of employees are prone to emotional exhaustion in view of their regular interaction with guests, and the expectations to regulate emotions at work resulting in consistent depletion of emotional resources. As a result, employees are unable to offer themselves psychologically at work. Such experiences could lead to burnout and consequently trigger other negative work behaviours (Hall et al., 2010). This is consistent with Francis et al. (2004) who considered emotional exhaustion alongside with depersonalisation, and low self-accomplishment as dimensions to understanding burnout in employee. While burnout is considered extreme condition under which other negative outcomes stem, emotional exhaustion creates the feeling of being emotionally over-stretched overtime resulting in psychological and physical strains.

Emotional exhaustion has attracted interest among researchers and practitioners alike in the service sector. Bolton, Harvey, Grawitch and Barber (2012) found strong association between emotional exhaustion and counter-productive work behaviour. That is, negative affect emanated from emotional exhaustion transcends employee well-being and quality of life to customer's impression of service quality and ultimately his or her satisfaction (Prakash, Jaramillo, \& Locander, 2006).

Studies have found leadership and emotion intertwined (Little, Gooty, \& Williams, 2016; Green, Miller, \& Aarons, 2013). This is because deep within leadership is the ability to inspire followership, ensuring healthy relationship at work, (Little, Gooty, \& Williams, 2016) by influencing employee positive work outcome 
such as job involvement (Han \& Park, 2013; Sheikh, Newman, \& Al Azzeh, 2013) commitment (Walumbwa, Orwa, Wang, \& Lawler, 2005), psychological ownership (Alok, 2014; Avey, Wernsing, \& Palanski, 2012) and job satisfaction (Fisk \& Friesen, 2012; Avey, Wernsing, \& Palanski, 2012). Similarly, effective leadership style relate negatively with job stress (Gill, Flaschner, \& Shachar, 2006) and emotional exhaustion (Wu \& Hu, 2009; Laschinger, Wong, \& Grau, 2013). Though the influence of various leadership styles on emotional exhaustion, psychological ownership and job satisfaction is well documented, there is paucity of empirical study on the predictive role of authentic leadership style on these work outcomes (Laschinger et al., 2013). Existing evidence in Alok (2014) which examined the relationship between authentic leadership and psychological ownership found that authentic leadership only relates with preventive psychological ownership otherwise known as territoriality but not with other aspects of psychological ownership such as self-efficacy, accountability, belonging and self-identity as defined in Avey, Avolio, Crossley and Luthans (2009), hence begs for further investigation.

In line with forgone, this study examines the mediating role of psychological ownership in the relationship between authentic leadership, job satisfaction and emotional exhaustion. Interestingly a search also reveals dearth of literature on the mitigating effect of psychological ownership on emotional exhaustion particularly in the hospitality industry and in a developing setting like Nigeria. In addition, justifying the need for this study in the Nigerian context is owed to its potentials as tourism destination as underscored in Ndajiya, Shehu and Yunusa (2014) with a capacity of becoming a continental hub in hospitality investment. A Price Waterhouse Cooper's report of 2015 predicted a more than double increase in the number of hotel rooms in Nigeria in the next 5years based on the $24 \%$ cumulative increase in 2010. It also reported that the sector attracted investment to the sum of 3 billion USD over the last 5years, providing huge employment opportunity to Nigerians. Having linked emotional labour, a common denominator in the service industry to emotional exhaustion, conducting this study in the Nigeria's growing hospitality industry is timely and relevant.

\section{Conceptual Framework and Hypotheses Development}

This study conceptualises ways of reducing emotional exhaustion among front line employees in the Nigerian hospitality industry in view of its preponderance among these category of work force. We therefore proposed based on empirical and theoretical evidences that authentic leadership style will associate negatively with emotional exhaustion, and positively with psychological ownership and job satisfaction. Similarly the study further posits that the relationship between authentic leadership, job satisfaction and emotional exhaustion is better explained through an intervening mechanism of psychological ownership as depicted in Figure1. These claims are further concretized in the next sub-sections.

\section{Authentic leadership}

The construct authentic leadership style is philosophically rooted in the real meaning of authenticity (Walumbwa, Avolio, Gardner, Wernsing, \& Peterson, 2008), which posits that authenticity leads to self-esteem. That is, individuals who are truthful to themselves and acknowledge their strengths and weaknesses tend to develop a stable self-esteem compared to pretentious and less matured individuals who often express defensive biases for their actions. In addition, the authentic nature in them is reflected in the hegemony between their values, beliefs and actions (Kernis, 2003), hence individual's values rather than external factors such as threats, social or financial influences guide his or her conduct (Ryan \& Deci, 2001). Suggesting that leaders with high level of authenticity tend to be real in dealing with life's challenges thereby experience high physical and psychological well-being (Walumbwa et al., 2008) as benefits derivable which in turn affects their perception and influences on others.

Consistent with the aforementioned, Walumbwa et al., (2008) in Joo et al., (2016:1121) defined authentic leadership as "a leadership style that promotes ethical climate and positive psychological capacities for the purpose of developing an internalized moral and ethical perspective, balanced sense of information processing, transparent relationship with followers, while nurturing self-awareness and self-development". Laschinger et al., (2013) Contend that leaders who are authentic share from their personal experiences in life, positive psychological attributes such as, hope, optimism, resilience, and self-efficacy, hence expresses high moral probity, and supportiveness resulting in creating a workplace that encourages greater self-awareness and self-regulated behaviours that impact positively (Avey et al., 2009). In other words, authentic leaders expresses leadership behaviours that best describe their transparent and ethical attributes, which ensure that high premium is placed on symmetrical information sharing and valuing the contributions of others (Avey et al., 2009; Laschinger et al., 2013). This enables them create a workplace where trust and other key attributes of authenticity, (i.e balanced processing, relational transparency, internalized moral perspectives and selfawareness) prevail (Laschinger et al., 2013; Spence, Wong, \& Grau, 2012; Walumbwa et al., 2008).

According to Spence, Wong and Grau (2012), Walumbwa et al. (2008) balanced processing attribute of authentic leaders enable them seek input and points of view of others which could be negative or positive 
Authentic Leadership, Emotional Exhaustion and Job Satisfaction in Nigerian Hospitality Industry..

before making any critical decision with underpinning effect on the entire organization. The aspect of rational transparency entails that a leader is being authentic in his self-presentation rather than a distorted or fake image (Walumbwa et al., 2008) which fall short of his or her core values. This encourages openness and information sharing with followers (Laschinger et al., 2013) consequently reduce the tendency of expressing negative emotion (Kernis, 2003) among employees. Similarly, internalised moral perspective in authentic leaders enable them cultivate high sense of self-regulation (Walumbwa et al., 2008). Leaders sense of self-regulation is not far fetch, but traceable to their internal moral standard and values which are considered helpful in ensuring that their behaviours and decision making are consistent with those values (Spence, Wong, \& Grau, 2012). Selfawareness character in authentic leadership explains how such leaders make meaning about the world round them which influences their views of themselves over time (Walumbwa et al., 2008). This attribute is greatly responsible for understanding their strengths and weaknesses and other implicit nature in them that enable them gain insight of themselves in relation to how their actions impact on others (Kernis, 2003)

Having understood the dimensions under which authentic leadership is hinged, we propose that leaders who possess these key attribute positive influence on their followers by increasing their attachment to the organization through psychological ownership. This we believe associates positively with job satisfaction and negatively with emotional exhaustion.

\section{Authentic Leadership and Emotional Exhaustion}

As established earlier, emotional exhaustion is major concern among employees particularly in the context of this study (Francis, Kaldor, Shevlin, \& Lewis, 2004; Hall et al. 2010). The need for affective delivery as expected in positive expression of emotion among the service interface is one unique attribute that enhances customer satisfaction (Grandey, 2003). Tan, Der Foo and Kwek (2004) have linked employees' positive emotions such as greeting, eye contact, warm smile and so forth as additional package for affective service delivery. In view of this, the demand for emotional labour among front-line workers tend to be on a rise (Martínez-iñigo et al., 2007), hence the tendency for emotional exhaustion become obvious. Scholars have operationalized emotional labour into surface and deep acting (Grandey, 2003; Deng, Walter, \& Guan, 2016). Where surface acting modifies facial expression and deep acting goes beyond the facial expression to trigger inner feelings (Grandey, 2003) giving rise to authentic behaviour in service delivery. Consistent with rational transparency factorial in authentic leadership which sued for a real self-presentation rather than a distorted or fake image (Walumbwa et al., 2008), we contend that, front line employees who are led by authentic leaders will tend to be real in their expression, hence engage in deep rather than surface acting. And since deep acting is associated with affective service delivery (Grandey, 2003), authentic leadership in employees who engage in deep acting is expected to attenuate emotional exhaustion. We therefore hypothesise that:

H1: Authentic leadership associates negatively with emotional exhaustion.

\section{Authentic Leadership and Job Satisfaction}

Job satisfaction is defined as employees' attitudinal evaluative judgment of their job experiences (Mustafa, Martin, \& Hughes, 2016), it also expresses their affective reaction (Wong \& Laschinger, 2012) to their job. Leadership, especially transformational style has been found to significantly influence employees' affective reaction towards their jobs (Braun, Peus, Weisweiler, \& Frey, 2013). Recently, (Penger \& Černe, 2014). Studies also established direct relationship (Olaniyan \& Hystad, 2016), indirect relationship between authentic leadership and job satisfaction through supportive professional practice environment (Fallatah, \& Laschinger, 2016), structural empowerment (Wong, \& Laschinger, 2012). However, a meta-analytical review reveals less prevalence of authentic leadership over transformational leadership in predicting followers' satisfaction at work (Banks, McCauley, Gardner, \& Guler, 2016) which is inconsistent with previous findings. This therefore necessitate the reassessment of this relationship.

Riding on the balanced processing factorial of authentic leaders (Spence, Wong \& Grau, 2012; Walumbwa et al., 2008) which encourages the seeking of input and points of view of their followers, regardless of the tone before making any critical decision that underpins the entire organization, resulting in sense inclusiveness in followers. Employee feeling of inclusiveness has a positive effect on job engagement and satisfaction (Randel, Dean, Ehrhart, Chung, \& Shore, 2016). Similarly, rational transparency factorial of authentic leaders which hinged on openness and information sharing with followers (Laschinger et al., 2013) reduces negative emotion (Kernis, 2003) in a work place. Consistent with the forgone, we argue that, front line employees who perceived leaders as authentic tend to feel a sense of inclusiveness at work, and thereby experience high job satisfaction. We therefore hypothesize that:

H2: Authentic leadership associates positively with job satisfaction 


\section{Authentic Leadership, Psychological Ownership and work outcome}

Psychological ownership is a state of intrinsic attachment in employee whereby he or she feels a sense of ownership in the organization in which he or she works (Mustafa et al., 2016; Song Lin, Lamond, Pan, Qin, \& Gao, 2014). In other words psychological ownership is defined as "the state in which individuals feel as though the target of ownership or a piece of that target is theirs" (Avey et al., 2009:174). According to Song et al. (2014) the construct in organizational research is derived from the sense of possession, self-conception and responsibility an individual has towards a target object. They added that employee sense of possession in organization leads to high affective involvement and protection, evident in the expression of positive organizational behaviour.

Authentic leadership has been found to relate positively with followers promotive sense of ownership (Alok, 2014) of organization and sense of ownership relates with positive organizational behaviour (Song et al., 2014). Though the relationship between authentic leadership and psychological ownership is established, the mediating role of psychological ownership between authentic leadership and work outcome such as job satisfaction and emotional exhaustion is still emerging. While we Concur with the findings of Alok (2014) on the positive association between authentic leadership and promotive psychological ownership factorial only, we further contend that the relationship will be more robust when the construct is considered as a whole using a different statistical instrument.

Furthermore, we found psychological ownership a suitable intervening variable between authentic leadership and work outcome on the basis that attributes such as balanced processing, rational transparency, internalized moral perspective and self-awareness character in authentic leadership (Spence, Wong, \& Grau, 2012; Laschinger et al., 2013; Walumbwa et al., 2008; Kernis, 2003) could influence PO. This explains how such leaders value the inputs of their followers, open to followers criticism and information sharing, make objective decision based on their core values and meaning they ascribe to the world round them which influence their view of themselves others. Front-line employees under these leaders are expected to feel valued, highly inclusive, and fairly treated. In a reciprocal gesture, they experience sense of possession, self-conception and responsibility towards the organization (Mustafa et al., 2016; Song Lin, Lamond, Pan, Qin, \& Gao, 2014) and in exchange (Cropanzano \& Mitchel, 2005; Blau, 1964) express high job satisfaction and low emotional exhaustion. We thus hypothesized that:

H3: Authentic leadership associates positively with psychological ownership.

H4A: Psychological Ownership mediates the relationship between authentic leadership and job satisfaction.

H4B: Psychological Ownership mediates the relationship between authentic leadership and emotional exhaustion.

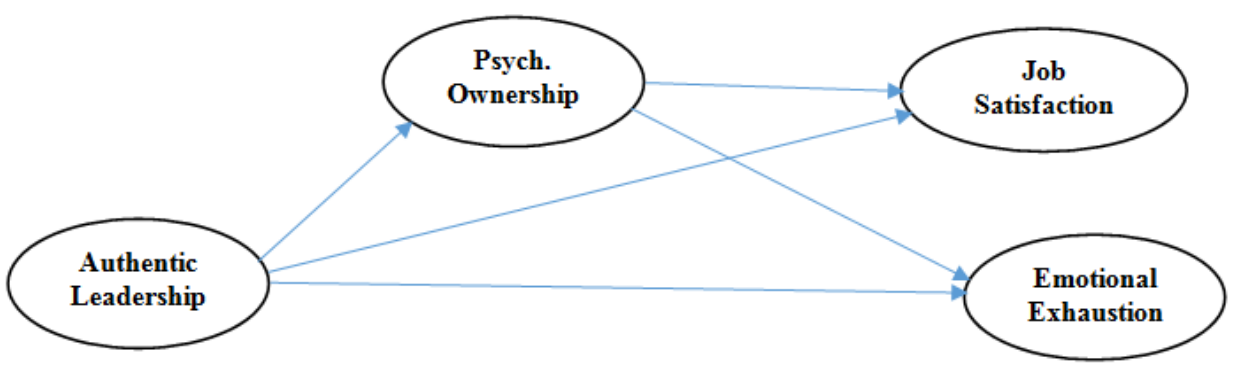

Figure 1. Conceptual Framework

\section{Methodology}

The study examined the mediating role of psychological ownership and the antecedent role of authentic leadership on job satisfaction and emotional exhaustion among front-line employees of Nigerian hospitality industry. To achieve this a sample of 350 front line employees were studied among some selected states in north central Nigeria, using self-response questionnaire survey. A cross sectional approach was adopted. In addition, the study followed a positivist research paradigm, and we used Structural Equation Modelling (SEM) variancebased (Smart-PLS) to analyse the data. The choice of the instrument is based on its robust predictive potency in behavioural science research (Hair Jr, Hult, Ringle, \& Sarstedt, 2013).

\section{Measures}

The questionnaire items in this study was adapted from previous studies based on their relevance to this study. These include; Authentic leadership (Walumbwa et al., 2008), Psychological Ownership (Avey et al., 2009), Job Satisfaction (Konrad et al., 1999) and Emotional Exhaustion (Kristensen, Borritz, Villadsen, \& Christensen, 2005) 
Authentic Leadership, Emotional Exhaustion and Job Satisfaction in Nigerian Hospitality Industry..

\section{Authentic Leadership}

Authentic Leadership Questionnaire (ALQ) developed and validated by Walumbwa et al. (2008) was used to measure leadership behavior from the front-line perspective, which require followers reporting on the leaders. ALQ is on 8-items which was developed based on 4-dimensions with 2-tems each. This study analyzed authentic leadership at the contruct level, and hence considered the 8-items as a whole. Sample of the questionnaire items as modified require the respondents to rate their leaders on a 7-point Likert-typed scale ranging from strongly agree to strongly disagree. Example "My manager seeks feedback to improve interactions with others", "My manager listens carefully to different points of view before coming to conclusions".

\section{Psychological Ownership}

Psychological Ownership measure was adapted from Avey et al. (2009). From the original scale, 10items were adapted after a pre-testing of the items based on their simplicity and consistency to the context of this study. Front line employees reported their level of psychological ownership on a 7-point likert-typed questionnaire. Sample of the questionnaires include; "I am confident I can make a positive difference in this organization", "I feel this organization's success is my success".

\section{Job Satisfaction}

Job Satisfaction measure used for this study was adapted from Konrad et al. (1999). The measure comprises of other aspects of satisfaction, this study considered items relevant to job. It is a 3-item questionnaire, measured on 7-point likert-typed scale and has the following as sample, "Overall I am satisfied with my work", "Knowing what I know now, I would, without any hesitation choose the same position if I had to decide all over again", "The position I am in measures up to the sort of position I had aspired".

\section{Emotional Exhaustion}

We used 6-items measure adapted from Copenhagen Burnout Inventory (CBI) developed by Kristensen, Borritz, Villadsen and Christensen (2005). The scale was developed to assess the level of emotional exhaustion among physicians emanating from interaction with clients or patients. Sample of the questionnaire items include; "I find working with clients irritating", "I sometimes wonder how long I will continue working with these number of clients".

\section{Descriptive Statistics}

\section{Result}

Though proponent of Variance-based SEM (Hair Jr et al., 2013; Hair Jr, Sarstedt, Hopkins, \& Kuppelwieser, 2014) have argued that when using PLS-SEM normality requirement in data is relatively important, notwithstanding we ensured normality is ascertained. Normality test was conducted and result presented in Table 1. Result indicates that the measures of central tendency (mean and standard deviation) meets normality requirement on a 7-point Likert typed scale. Similarly, skewness and kurtosis value falls between -1 and 1, indicating that the normality requirement of the data is met (Joe F. Hair, Ringle, \& Sarstedt, 2011). In addition the strength of relationship correlation coefficient ranges 0.70 (very strong), 0.51 (Average) and 0.31 (weak) (Chua, 2013).

Table 1 Descriptive Statistics and Correlation Assessment

\begin{tabular}{|r|l|c|c|c|r|r|c|c|c|}
\hline & Mean & $\begin{array}{c}\text { Std. } \\
\text { Deviation }\end{array}$ & Skewness & Kurtosis & 1 & 2 & 3 & 4 \\
\hline 1 & Authentic leadership & 3.8870 & 1.02420 & -1.220 & .444 & 1 & & \\
\hline 2 & Psyc. Ownership & 4.3219 & 1.23591 & -.137 & -1.386 & $.381^{* *}$ & 1 & \\
\hline 3 & Emotional Exhaustion & 3.7944 & 1.37722 & .121 & -1.336 & $-.331^{* *}$ & $-.658^{* *}$ & 1 & \\
\hline 4 & Job Satisfaction & 4.3272 & 1.38844 & -.201 & -1.302 & $.355^{* *}$ & $.863^{* *}$ & $-.636^{* *}$ & 1 \\
\hline
\end{tabular}

Criteria: ** Correlation is significant at the 0.01 level (2-tailed).

\section{Data Analysis}

In analysing the data collected to ascertain the relationship conceptualized in the framework in figure 1, Partial Least Square (PLS) Version 3.0 was used. The analysis was done in 2 phases (Anderson \& Gerbing, 1988) to enable us assess first, the measurement model and secondly, the structural model. The assessment of the measurement model was conducted to establish the convergent validity and discriminant validity, while structural model examines the path coefficient in line with the proposed hypotheses, and other relevant tests (Yeap, Ramayah, \& Soto-Acosta, 2016; Hair et al., 2011; Hair Jr et al., 2014). 
Authentic Leadership, Emotional Exhaustion and Job Satisfaction in Nigerian Hospitality Industry..

\section{Assessment of Measurement Model}

In order to evaluate the measurement model, a convergent and discriminant validity were examined. First the convergent validity measures the extent to which indicator or measure correlate with alternative indicators or measures of the same construct (Hair Jr, Hult, Ringle, \& Sarstedt, 2016) and it is examined through the following coefficients, factor loading, composite reliability (CR) and average variance extracted (AVE) (Yeap et al., 2016; Lo, Ramayah, Isa, \& Jais, 2013). Based on the results in Table 2, all factor loadings were at least 0.7, the composite reliabilities were all higher than 0.7 while the AVE values for all the constructs were also higher than 0.5, suggesting that convergent validity requirements are not violated (Hair et al., 2011; Hair et al., 2014)

Table 2 Assessing Convergent Validity

\begin{tabular}{|l|l|c|c|c|}
\hline Construct & Item & Loading & CR & AVE \\
\hline Authentic Leadership & AUTHEN1 & 0.819 & 0.892 & 0.625 \\
\hline & AUTHEN2 & 0.810 & & \\
\hline & AUTHEN3 & 0.867 & & \\
\hline & AUTHEN4 & 0.841 & & \\
\hline & AUTHEN5 & 0.763 & & \\
\hline & AUTHEN6 & 0.702 & & \\
\hline & AUTHEN7 & 0.666 & & \\
\hline Emotional Exhaustion & AUTHEN8 & 0.834 & & \\
\hline & EMOEX1 & 0.688 & 0.903 & 0.609 \\
\hline & EMOEX2 & 0.828 & & \\
\hline & EMOEX3 & 0.826 & & \\
\hline & EMOEX4 & 0.767 & & \\
\hline & EMOEX5 & 0.847 & & \\
\hline Job Satisfaction & EMOEX6 & 0.712 & & \\
\hline & JSat1 & 0.920 & 0.934 & 0.824 \\
\hline & JSat2 & 0.923 & & \\
\hline Psychological Ownership & JSat3 & 0.881 & & \\
\hline & PSYCH1 & 0.891 & 0.960 & 0.776 \\
\hline & PSYCH3 & 0.901 & & \\
\hline & PSYCH5 & 0.908 & & \\
\hline & PSYCH6 & 0.845 & & \\
\hline & PSYCH7 & 0.883 & & \\
\hline & PSYCH9 & 0.854 & & \\
\hline & PSYCH10 & 0.884 & & \\
\hline
\end{tabular}

Note: Items PSYCH2, PSYCH4, PSYCH8 were deleted for low correlation with construct

The discriminant validity of the measures was examined to establish the extent to which items or constructs are distinct from other measures within the structural model. Following the assessment, using Fornell and Larcker (1981) criterion, we compare the correlations between constructs and square root of AVE for that construct, (see Table 3). Based on the result, the square root of the AVEs are represented by the values bolded diagonally which are greater than the correlation of the corresponding row and column, hence discriminant validity is established (Hair et al., 2011; Hair et al., 2014).

Table 3 Assessing Discriminant Validity Fornell-Larcker Approach

\begin{tabular}{|l|l|c|c|c|c|}
\hline & \multicolumn{1}{|c|}{ Constructs } & 1 & 2 & 3 & 4 \\
\hline 1 & Authentic Leadership & $\mathbf{0 . 7 9 1}$ & & & \\
\hline 2 & Emotional Exhaustion & -0.337 & $\mathbf{0 . 7 8}$ & & \\
\hline 3 & Job Satisfaction & 0.364 & -0.642 & $\mathbf{0 . 9 0 8}$ & \\
\hline 4 & Psychological Ownership & 0.373 & -0.663 & 0.764 & $\mathbf{0 . 8 8 1}$ \\
\hline
\end{tabular}

\section{Assessment of Structural Model}

In order to assess the structural model or the latent relationships, a bootstrapping procedure was conducted to determine the beta value, $\mathrm{R}^{2}$ and t-value (Hair et al., 2014) in the hypothesized relationships. Along with that is the effect size $\left(\mathrm{f}^{2}\right)$ and the predictive relevance $\left(\mathrm{Q}^{2}\right)$, (Hair et al., 2012; Yeap et al., 2016) as well as the mediating role of psychological ownership. 
First, we evaluate the relationship in $\mathrm{H} 1$ between authentic leadership and emotional exhaustion. The results in Table $4(\beta=-0.104, p<0.01)$ shows that authentic leadership associate negatively with emotional exhaustion, explaining $44.9 \%$ of variance. Secondly the relationship in $\mathrm{H} 2$ between authentic leadership and job satisfaction was examined, results shows $(\beta=0.048, \mathrm{p}=0.051)$. Though authentic leadership associate positively with job satisfaction, it is considered statistically insignificant since the $\mathrm{p}$ and t-values of 0.051 and 1.641 are greater than 0.05 and less than 1.96 threshold respectively. Thirdly, H3 testing the relationship between authentic leadership and psychological ownership was evaluated with $(\beta=0.373, p<0.01)$ revealing a positively significant relationship between authentic leadership and psychological ownership explaining $13.9 \%$ variance.

Furthermore we examined these relationship in terms of their substantial significance through the effect size $\left(\mathrm{f}^{2}\right)$ and the predictive relevance $\left(\mathrm{Q}^{2}\right)$. For the effect size $\left(\mathrm{f}^{2}\right)$ which evaluates the impact of exogenous latent constructs on the structural model, Cohen (1988) provides a guideline for such assessment as 0.02 (small), 0.15 (medium), and 0.35(large). Based on this guideline, the effect size between authentic leadership and emotional exhaustion of 0.017 as small, the effect size between authentic leadership and job satisfaction of 0.008 as very insignificant while that of authentic leadership and psychological ownership of 0.162 as medium. Regarding the predictive relevance $\left(\mathrm{Q}^{2}\right)$ of the indicators on the structural model, a blindfolding analysis conducted, and results as presented in Table 4. Hair et al. (2011: 2014), posits that a construct has predictive relevance when $\mathrm{Q}^{2}>0$. Consistent with that criterion the coefficients $(0.265,0.615 \& 0.107)$ obtained from the endogenous constructs in $\mathrm{H} 1, \mathrm{H} 2$ \& $\mathrm{H} 3$ are said to have high predictive relevance.

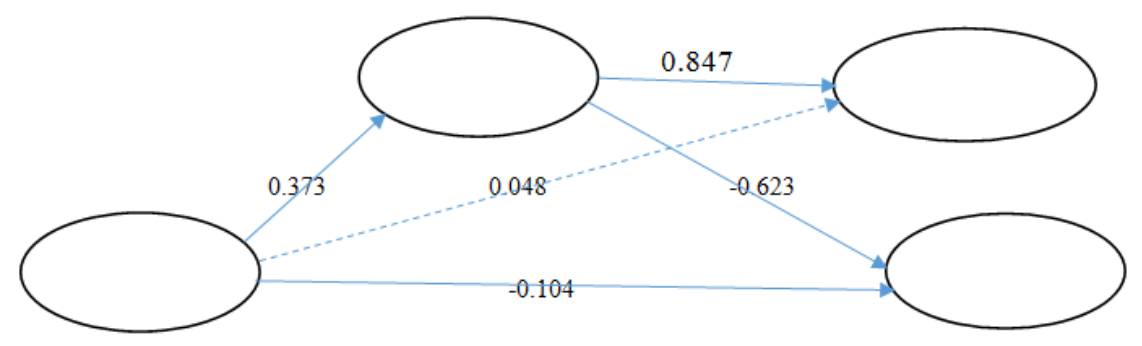

Table 4 Result of Structural Model

\begin{tabular}{|c|c|c|c|c|c|c|c|c|}
\hline Hypotheses & Relationship & Std Beta & Std Error & t-value & Decision & $\mathrm{R}^{2}$ & $\mathrm{~F}^{2}$ & $\mathrm{Q}^{2}$ \\
\hline H1 & AL-EE & -0.104 & 0.042 & $2.488^{* *}$ & Supported & 0.449 & 0.017 & 0.265 \\
\hline H2 & AL-JS & 0.048 & 0.029 & 1.641 & Not Supp. & 0.749 & 0.008 & 0.615 \\
\hline H3 & AL-PO & 0.373 & 0.043 & $8.592^{* *}$ & Supported & 0.139 & 0.162 & 0.107 \\
\hline
\end{tabular}

**P<0.01, where AL: Authentic Leadership, EE: Emotional Exhaustion, JS: Job Satisfaction, PO: Psychological Ownership

Additional analysis was conducted to evaluate the mediating role of psychological ownership in the relationship between authentic leadership, job satisfaction and emotional exhaustion using bootstrapping procedure (Preacher \& Hayes, 2008). Results reveal a strong indirect relationship in line with Preacher and Hayes (2008) and Hair et al. (2013) first and second criteria (see Table 5). The result shows a complementary mediation (Hair, Hult, Ringle, \& Sarstedt, 2016) for (H4A) since both direct and indirect relationships are significant (Table 4 and Table 5). And indirect relationship in (H4B) since only the indirect relationship is significant (Table 4 and Table 5). Based on the criteria, the t-value in both indirect relationships are above the threshold value of 1.96. Secondly in the indirect effects neither of the $95 \%$ confidence intervals include zero (Hair et al, 2017) suggesting a strong mediating effect.

Table 5 Assessing Mediating Role of Psychological Ownership

\begin{tabular}{|c|c|c|c|c|c|c|c|}
\hline Hypotheses & Relationship & Std Beta & $\begin{array}{c}\text { Standard } \\
\text { Error }\end{array}$ & $\begin{array}{c}\text { Lower Class } \\
\text { Limit }\end{array}$ & $\begin{array}{c}\text { Upper Class } \\
\text { Limit }\end{array}$ & T Stat. & Decision \\
\hline H4A & AL ->PO-> EE & -0.233 & 0.033 & -0.291 & -0.186 & $7.152^{* *}$ & Supported \\
\hline H4B & AL -> PO->JS & 0.316 & 0.038 & 0.253 & 0.38 & $8.256^{* *}$ & Supported \\
\hline
\end{tabular}

**P<0.01, where AL: Authentic Leadership, EE: Emotional Exhaustion, JS: Job Satisfaction, PO: Psychological Ownership

\section{Discussion}

This study was conducted to determine the factors that could reduce emotional exhaustion and ensure job satisfaction among front line employees in Nigerian hospitality industry through the predictive lens of authentic leadership and a mediating role of psychological ownership. In line with the authentic leadership theory and social exchange theory, we propounded and tested four hypotheses. The prediction in H1 which is underpins on rational transparency factorial of authentic leadership, where real self-presentation rather than a 
distorted or fake image (Walumbwa et al., 2008) in leadership is emphasized. Which implies that front line employees who are led by authentic leaders tend to be influenced by same leadership style resulting in deep rather than surface acting in emotional labour. In view of the role of deep acting on affective service delivery (Grandey, 2003), the strong negative association of authentic leadership with emotional exhaustion is logical and consistent.

However, the relationship between authentic leadership and job satisfaction in $\mathrm{H} 2$ was not supported statistically since the t-value was 1.64 lower than the threshold value of 1.96 even though it relates positively as proposed. Finding in the current study is consistent with the work of Banks, McCauley, Gardner and Guler, (2016) which reveals less prevalence of authentic leadership in predicting followers' satisfaction at work. This, suggests an indirect relationship between the two construct as we predicted in the mediating role of psychological ownership.

The relationship between authentic leadership and psychological ownership as proposed in $\mathrm{H} 3$ is positive as hypothesized in the current study and statistically significant. Implying that front line employees who perceived leaders as authentic, feel part and parcel of the organization, since the leaders seek their inputs in making critical decision, by allowing them to voice their concerns. Furthermore the assurance received from a leader who is transparent and integrate his experiences at work with his core value (Spence, Wong, \& Grau, 2012; Laschinger et al., 2013; Walumbwa et al., 2008; Kernis, 2003) is capable of infusing positive affect at work by exerting similar influences on followership since successful leadership could be a model to followers. This justifies the strong association between leadership and psychological ownership in previous studies (Mustafa et al., 2016; Song Lin, Lamond, Pan, Qin, \& Gao, 2014).

Psychological ownership was found to mediate the relationship between authentic leadership and job satisfaction which heretofore was insignificant. This suggests that authentic leadership associate indirectly with job satisfaction, in line with result in H4A. That is, front line employees who express high psychological ownership at work tend to experience job satisfaction while those with low psychological ownership may tend to experience low satisfaction at work. Also in line with $\mathrm{H} 4 \mathrm{~B}$, result aligns with the earlier argument that, psychological ownership mediates the relationship between authentic leadership and emotional exhaustion. Suggesting a complimentary mediation (Hair, Hult, Ringle, \& Sarstedt, 2016) since both direct and indirect relationships are significant. Based on the inference drawn from this mediating relationship, front line employees who perceived their leaders as authentic tend to experience psychological ownership (Mustafa et al., 2016; Song Lin, Lamond, Pan, Qin, \& Gao, 2014), as such attenuate their feeling of emotional exhaustion, because they feel a sense of meaningfulness at work since their contribution to the organization is valued.

\section{Implication of Findings}

This study as mentioned earlier is interested in reducing negative effect of emotional labour which characterizes the job description of front line employees (Francis, Kaldor, Shevlin, \& Lewis, 2004; Hall et al. 2010), exposing them to high emotional exhaustion (Martínez-iñigo et al., 2007) hence, they experience less job satisfaction. Authentic leadership and psychological ownership were proposed as predictors and mediators respectively in reducing this negative tendency. We developed and evaluated a framework that helped in crystalizing our argument. In line with the results obtained, we inferred that authentic leadership predicts emotional exhaustion directly and indirectly through psychological ownership. Similarly, job satisfaction is also indirectly predicted through psychological ownership as well.

Theoretically, we address two gaps where paucity of literature exist and findings were inconclusive. First we established that limited empirical studies exist on the intervenning role of psychological ownership between authentic leadership on job satisfaction and emotional exahaustion. From our finding, authentic leadership is more meaningful when psychological ownership exist, since it provides better explanation on low or high job satisfation and emotional exhaustion occur. This buttresses the fact that leadership no matter real the intention might be, does not automatically translate into the desired end, rather the employee interface must perceive the intention as genuine and key into it. For example expression of balanced processing, relational transparency, internalized moral perspectives and self-awareness (Laschinger et al., 2013; Spence, Wong, \& Grau, 2012; Walumbwa et al., 2008) by authentic leaders is not enough a solution for employee job satisfaction neither it is a remedy to emotional exhaustion. Employee must buy into the essense of leadership and organizational core value(s).

Secondly, empirical evidences seem inconlusive on the direct relationship between authentic leadership job satisfaction (Banks, McCauley, Gardner, \& Guler, 2016), while dearth of literature linking authentic leadership and emotional exhaustion is established particularly as it relates to hospitality industry in emerging economy like ours. It is found to be weak on job satisfaction in the context of this study and very strong on emotional exhaustion. This finding agrees with the argument for prevalence of emotional labour and exhaustion (Francis, Kaldor, Shevlin, \& Lewis, 2004; Hall et al. 2010; Martínez-iñigo et al., 2007) in the service industry. Employee may find authentic leaders as supportive, and empathetic of their work related stress, resulting in 
Authentic Leadership, Emotional Exhaustion and Job Satisfaction in Nigerian Hospitality Industry..

developing positive mind-set through deep acting thereby reduces emotional exhaustion. (Grandey, 2003; Deng, Walter, \& Guan, 2016).

Practically, the findings in this study offers insight on the role of authentic leadership in attenuating negative work outcome. In view of the forgone, since it is apparent that leadership has a significant impact on followers' job related behaviour, decision makers in hospitality industry must not pay lip-service to leadership development programme. This will ensure that the right people with authentic leadership attributes are identified and nurtured to bring the desired impact on the organization.

Similarly, having established that psychological ownership mediates the relationship between leadership, job satisfaction and emotional exhaustion, leaders in hospitality industry must ensure that employees are given opportunity to have a say, particularly on issues critical to their development on the job, welfare, strategic matter related to investment and divestment etcetera. When an employee feels that his or her opinion counts, he or she will not only be physically present at work but psychologically attached to the organization as well (Mustafa et al., 2016; Song Lin, Lamond, Pan, Qin, \& Gao, 2014). When front line workers are positively attached, they express deep acting rather than surface acting (Grandey, 2003), increased service quality as seen in positive emotions such as greeting, eye contact, warm smile (Tan, Der Foo \& Kwek, 2004). And since employee interface between organization and the customer is very key (Jonathan \& Johnmark, 2012), the need to spur sense of ownership is even critical in an emerging hospitality industry like Nigeria. Doing so will impacting positively and thereby deepens customer loyalty.

\section{Conclusion}

Based on the outcome of the roles of leadership and psychological ownership in predictive emotional exhaustion and job satisfaction, authentic leadership was found to relate negatively and significantly with emotional exhaustion. Which suggests that emotional exhaustion which is common among employees in service sector could be reduced with effective leadership. The direct relationship with job satisfaction was positive but not significant suggesting a possibility of an indirect relationship which earlier anticipated in psychological ownership at the conceptualization stage. Findings also underscores the significance of psychological ownership as an intervening variable between the predictor, emotional exhaustion and job satisfaction. Finally we sued for the integration of authentic leadership in view of its mitigating effect on emotional exhaustion and positive effect on employee psychological ownership. Similarly, key decision makers in the hospitality industry and other service related organizations are encouraged to pay attention to the prevailing style of leadership among their line managers. Doing so will no doubt create a sense of meaningfulness (Hackman \& Oldham, 1976), a situation whereby employees feel valued and their inputs counts in the organization. This feeling has an intriguing effect on the perception employee's work life thereby ensuring high job satisfaction and low emotional exhaustion as explained by the intervening role of psychological ownership.

\section{Reference}

[1]. Alok, K. (2014). Authentic leadership and psychological ownership: investigation of interrelations. Leadership \& Organization Development Journal, 35(4), 266-285.

[2]. Anderson, J. ., \& Gerbing, D. . (1988). Structural Equation Modelling In Practice: A Review And Recommended Two-Step Approach. .Psychological Bulletin, 103, 411-423, 103(3), 411-423.

[3]. Avey, J. B., Avolio, B. J., Crossley, C. D., \& Luthans, F. (2009). Psychological ownership: Theoretical extensions, measurement and relation to work outcomes. Journal of Organizational Behavior, 30(2), 173-191.

[4]. Avey, J. B., Wernsing, T. S., \& Palanski, M. E. (2012). Exploring the process of ethical leadership: The mediating role of employee voice and psychological ownership. Journal of Business Ethics, 107(1), 21-34.

[5]. Banks, G. C., McCauley, K. D., Gardner, W. L., \& Guler, C. E. (2016). A meta-analytic review of authentic and transformational leadership: A test for redundancy. The Leadership Quarterly, 27(4), 634-652. JOUR.

[6]. Blau, P. M. (1964). Exchange and power in social life. London: Transaction Publishers.

[7]. Bolton, L. R., Harvey, R. D., Grawitch, M. J., \& Barber, L. K. (2012). Counterproductive work behaviours in response to emotional exhaustion: A moderated mediational approach. Stress and Health, 28(3), 222-233.

[8]. Braun, S., Peus, C., Weisweiler, S., \& Frey, D. (2013). Transformational leadership , job satisfaction , and team performance : A multilevel mediation model of trust is. The Leadership, 24, 270-283.

[9]. Callahan, J. L., \& McCollum, E. E. (2002). Obscured variability: The distinction between emotion work and emotional labor. Managing Emotions in the Workplace, 219-231.

[10]. Chua, Y. P. (2013). Mastering research statistics. Malaysis: McGraw-Hill Education.

[11]. Cohen, J. (1988). Statistical power analysis for the behavioural sciences. Hillside. NJ: Lawrence Earlbaum Associates.

[12]. Cropanzano, R. and M. S. M. (2005). Social Exchange Theory: An Interdisciplinary Review. Journal of Management, 31(6), 874 900.

[13]. Deng, H., Walter, F., \& Guan, Y. (2016). A Dual-pathway Model of Supervisor-directed Surface and Deep Acting. In Academy of Management Proceedings (Vol. 2016, p. 10968). CONF, Academy of Management.

[14]. F. Hair Jr, J., Sarstedt, M., Hopkins, L., \& G. Kuppelwieser, V. (2014). Partial least squares structural equation modeling (PLSSEM) An emerging tool in business research. European Business Review, 26(2), 106-121.

[15]. Fallatah, F. \& H. K. L. (2016). The influence of authentic leadership and supportive professional practice environments on new graduate nurses ' job satisfaction. Journal of Research in Nursing 2016, 21(2), 125-136.

[16]. Fisk, G. M., \& Friesen, J. P. (2012). Perceptions of leader emotion regulation and LMX as predictors of followers' job satisfaction and organizational citizenship behaviors. The Leadership Quarterly, 23(1), 1-12. 
Authentic Leadership, Emotional Exhaustion and Job Satisfaction in Nigerian Hospitality Industry..

[17]. Flanagan, N. A., \& Flanagan, T. J. (2002). An analysis of the relationship between job satisfaction and job stress in correctional nurses. Research in Nursing \& Health, 25(4), 282-294.

[18]. Fornell, C., \& Larcker, D. F. (1981). Structural equation models with unobservable variables and measurement error: Algebra and statistics. Journal of Marketing Research, 382-388.

[19]. Francis, L. J., Kaldor, P., Shevlin, M., \& Lewis, C. A. (2004). Assessing-emotional exhaustion among the Australian clergy: Internal reliability and construct validity of the scale of emotional exhaustion in ministry (SEEM). Review of Religious Research, 269-277.

[20]. Gill, A. S., Flaschner, A. B., \& Shachar, M. (2006). Mitigating stress and burnout by implementing transformational-leadership. International Journal of Contemporary Hospitality Management, 18(6), 469-481.

[21]. Grandey, A. A. (2003). When "the show must go on": Surface acting and deep acting as determinants of emotional exhaustion and peer-rated service delivery. Academy of Management Journal, 46(1), 86-96.

[22]. Green, A. E., Miller, E. A., \& Aarons, G. A. (2013). Transformational leadership moderates the relationship between emotional exhaustion and turnover intention among community mental health providers. Community Mental Health Journal, 49(4), $373-379$.

[23]. Hackman, J. R., \& Oldham, G. R. (1976). Motivation through the design of work: Test of a theory. Organizational Behavior and Human Performance, 16(2), 250-279.

[24]. Hair, J. F., Ringle, C. M., \& Sarstedt, M. (2011). PLS-SEM: Indeed a Silver Bullet. The Journal of Marketing Theory and Practice, 19(2), 139-152.

[25]. Hair, J. F., Sarstedt, M., Pieper, T. M., \& Ringle, C. M. (2012). The Use of Partial Least Squares Structural Equation Modeling in Strategic Management Research: A Review of Past Practices and Recommendations for Future Applications. Long Range Planning, 45(5-6), 320-340.

[26]. Hair Jr, J. F., Hult, G. T. M., Ringle, C., \& Sarstedt, M. (2013). A primer on partial least squares structural equation modeling (PLS-SEM). Los Angeles: Sage Publications.

[27]. Hair Jr, J. F., Hult, G. T. M., Ringle, C., \& Sarstedt, M. (2016). A primer on partial least squares structural equation modeling (PLS-SEM). BOOK, Sage Publications.

[28]. Hall, G. B., Dollard, M. F., Tuckey, M. R., Winefield, A. H., \& Thompson, B. M. (2010). Job demands, work- family conflict, and emotional exhaustion in police officers: A longitudinal test of competing theories. Journal of Occupational and Organizational Psychology, 83(1), 237-250.

[29]. Han, Y., \& Park, Y. (2013). Effects of self-leadership and job involvement on clinical competence in general hospital nurses. Journal of Korean Academy of Nursing Administration, 19(4), 462-469.

[30]. Jonathan, V. L., \& Johnmark, D. R. (2012). The Impact of Employee Empowerment on Customer Satisfaction in the Nigerian Service Organizations (A Study of Some Selected Hotels in Jos, Plateau State). International Journal of Current Research and Review, 4(19), 37

[31]. Joo, B.-K., Joo, B.-K., Lim, D. H., Lim, D. H., Kim, S., \& Kim, S. (2016). Enhancing work engagement: The roles of psychological capital, authentic leadership, and work empowerment. Leadership \& Organization Development Journal, 37(8), $1117-1134$.

[32]. Kernis, M. H. (2003). Toward a conceptualization of optimal self-esteem. Psychological Inquiry, 14(1), 1-26.

[33]. Konrad, T. R., Williams, E. S., Linzer, M., McMurray, J., Pathman, D. E., Gerrity, M., ... Rhodes, E. (1999). Measuring physician job satisfaction in a changing workplace and a challenging environment. Medical Care, 1174-1182.

[34]. Kristensen, T. S., Borritz, M., Villadsen, E., \& Christensen, K. B. (2005). The Copenhagen Burnout Inventory: A new tool for the assessment of burnout. Work \& Stress, 19(3), 192-207.

[35]. Laschinger, H. K. S., Wong, C. A., \& Grau, A. L. (2013). Authentic leadership, empowerment and burnout: a comparison in new graduates and experienced nurses. Journal of Nursing Management, 21(3), 541-552.

[36]. Lewig, K. A., \& Dollard, M. F. (2003). Emotional dissonance, emotional exhaustion and job satisfaction in call centre workers. European Journal of Work and Organizational Psychology, 12(4), 366-392.

[37]. Little, L. M., Gooty, J., \& Williams, M. (2016). The role of leader emotion management in leader - member exchange and follower outcomes. The Leadership Quarterly, 27(1), 85-97.

[38]. Lo, M. C. Ramayah, T. Isa, A.B. Jais, M. (2013). Leadership styles and financial services performance Abu Hassan Md Isa and Mohamad Jais. International Journal of Management Practice, 6(4), 299-319.

[39]. Martínez-iñigo, D., Totterdell, P., \& Alcover, C. M. (2007). Work \& Stress: An International Journal of Work , Health \& Organisations Emotional labour and emotional exhaustion: Interpersonal and intrapersonal mechanisms. International Journal of Work, Health \& Organization, 21(1), 30-47.

[40]. Mustafa, M., Martin, L., \& Hughes, M. (2016). Psychological Ownership , Job Satisfaction , and Middle Manager Entrepreneurial Behavior. Journal of Leadership \& Organizational Studies, 1(16), 1-16.

[41]. Ndajiya, A., Shehu, M., \& Yunusa, H. M. (2014). THE POSSIBLE IMPACT OF TOURISM INDUSTRY ON NIGERIA ECONOMY. Review of Public Administration and Management, 3(5), 68-75.

[42]. Olaniyan, O. S., \& Hystad, S. W. (2016). Employees' psychological capital, job satisfaction, insecurity, and intentions to quit: The direct and indirect effects of authentic leadership. Revista de Psicología Del Trabajo Y de Las Organizaciones, 32(3), 163-171.

[43]. Penger, S., \& Černe, M. (2014). Authentic leadership, employees’ job satisfaction, and work engagement: A hierarchical linear modelling approach. Economic Research-Ekonomska Istraživanja, 27(1), 508-526.

[44]. Prakash, J., Jaramillo, F., \& Locander, W. B. (2006). Emotional exhaustion and organizational deviance: Can the right job and a leader's style make a difference? Journal of Business Research, 59, 1222-1230.

[45]. Preacher, K. J., \& Hayes, A. F. (2008). Asymptotic and resampling strategies for assessing and comparing indirect effects in multiple mediator models. Behavior Research Methods, 40(3), 879-891.

[46]. Randel, A. E., Dean, M. A., Ehrhart, K. H., Chung, B., \& Shore, L. (2016). Leader inclusiveness, psychological diversity climate, and helping behaviors. Journal of Managerial Psychology, 31(1), 216-234.

[47]. Ryan, R. M., \& Deci, E. L. (2001). On happiness and human potentials: A review of research on hedonic and eudaimonic wellbeing. Annual Review of Psychology, 52(1), 141-166.

[48]. Sheikh, A. Z., Newman, A., \& Al Azzeh, S. A.-F. (2013). Transformational leadership and job involvement in the Middle East: the moderating role of individually held cultural values. The International Journal of Human Resource Management, 24(6), 10771095

[49]. Song Lin and Professor David Lamond, P., Pan, X.-F., Qin, Q., \& Gao, F. (2014). Psychological ownership, organization-based self-esteem and positive organizational behaviors. Chinese Management Studies, 8(1), 127-148.

[50]. Spence, H. K., Wong, C. A., \& Grau, A. L. (2012). International Journal of Nursing Studies The influence of authentic leadership on newly graduated nurses, experiences of workplace bullying, burnout and retention outcomes: A cross-sectional study. 
International Journal of Nursing Studies, 49(10), 1266-1276.

[51]. Tan, H. H., Der Foo, M., \& Kwek, M. H. (2004). The effects of customer personality traits on the display of positive emotions. Academy of Management Journal, 47(2), 287-296.

[52]. Walumbwa, F. O., Avolio, B. J., Gardner, W. L., Wernsing, T. S., \& Peterson, S. J. (2008). Authentic leadership: Development and validation of a theory-based measure. Journal of Management, 34(1), 89-126.

[53]. Walumbwa, F. O., Orwa, B., Wang, P., \& Lawler, J. J. (2005). Transformational leadership, organizational commitment, and job satisfaction: A comparative study of Kenyan and US financial firms. Human Resource Development Quarterly, 16(2), 235-256.

[54]. Wong, C. A., \& Laschinger, H. K. (2013). Authentic leadership, performance, and job satisfaction: the mediating role of empowerment. Journal of advanced nursing, 69(4), 947-959.

[55]. Wu, T.-Y., \& Hu, C. (2009). Abusive supervision and employee emotional exhaustion: Dispositional antecedents and boundaries. Group \& Organization Management, 34(2), 143-169.

[56]. Yeap, J. A. L., Ramayah, T., \& Soto-Acosta, P. (2016). Factors propelling the adoption of m-learning among students in higher education. Electronic Markets, 1-16. 